\title{
The Moral Entrepreneur: A New Component of Ethical Leadership
}

\author{
Muel Kaptein ${ }^{1}$
}

Received: 26 September 2016/Accepted: 5 July 2017/Published online: 21 July 2017

(C) The Author(s) 2017. This article is an open access publication

\begin{abstract}
Ethical leadership has become a popular subject of empirical research in recent years. Most studies follow Brown et al.'s (Organ Behav Hum Decis Process, 97:117-134, 2005) definition of ethical leadership, which consists of two components: the moral person and the moral manager. In this paper, I argue for a third relevant component: i.e., the moral entrepreneur who creates a new ethical norm. Viewing moral entrepreneurship as a new component of ethical leadership opens up avenues for studying various antecedents and outcomes of ethical leadership that have not been acknowledged so far, or at least, not adequately.
\end{abstract}

Keywords Ethical leadership · Corporate social responsibility - Social development - Proactive leadership · Moral entrepreneurship

The subject of ethical leadership has received much scholarly attention in recent years (Den Hartog 2015). The meta-analytic review of Bedi et al. (2016) includes no less than 134 empirical studies on the antecedents and outcomes of ethical leadership. Recent work on the outcomes of ethical leadership includes Zhu et al.'s (2015) study of

Editors at the Journal of Business Ethics are recused from all decisions relating to submissions with which there is any identified potential conflict of interest. Submissions to the Journal of Business Ethics from editors of the journal are handled by a senior independent editor at the journal and subject to full double blind peer review processes.

\section{Muel Kaptein}

mkaptein@rsm.nl

1 RSM Erasmus University Rotterdam, Room T11-52, P.O. Box 1730, 3000 DR Rotterdam, The Netherlands the relationship between ethical leadership and follower voice and performance; Zheng et al.'s (2015) investigation of the effects of ethical leadership on emotional exhaustion of followers; and Van Gils et al.'s (2015) exploration of the impact of ethical leadership on follower's organizational deviance. Studies of the antecedents of ethical leadership, at both the situational and personal levels, have found that leaders who have had ethical role models are more likely to become ethical leaders (Brown and Treviño 2014). These studies have also found that the personality traits of agreeableness and conscientiousness are positively related to ethical leadership (Kalshoven et al. 2011a).

There seems to be a general consensus on the meaning of ethical leadership despite the variety of research topics on the subject. Brown et al.'s (2005, p. 120) definition of ethical leadership as "the demonstration of normatively appropriate conduct through personal actions and interpersonal relationships, and the promotion of such conduct to followers through two-way communication, reinforcement, and decision-making" is widely accepted without much discussion. This definition is used in most ethical leadership studies (e.g., Avey et al. 2011; Bedi et al. 2016; Chughtai et al. 2015; DeConinck 2015; Kalshoven et al. 2011a, b; Mayer et al. 2012; Mo and Shi 2017; Piccolo et al. 2010; Rubin et al. 2010; Walumbwa et al. 2011; Walumbwa and Schaubroeck 2009). Only a few scholars, such as Eisenbeiß (2012) and Voegtlin et al. (2012), have raised any criticism about it. The wide adoption of this definition, which is based on social learning, is remarkable because Brown et al. presented this concept as relevant only to their research. They made no claims of advancing a general definition of ethical leadership; their definition was "for here" (Brown et al. 2005, p. 120).

Given that most empirical studies on ethical leadership are based on Brown et al.'s definition, the question is 
whether this definition is generally valid. If it is not, then what are the implications for the generalizability of the results of those studies? This paper reviews the definition of Brown et al. but uses social development instead of social learning as the lens with which to study ethical leadership. This paper argues that ethical leadership does not only follow ethics but that it also leads it. To make this argument, I use Carroll's (1979) typology of corporate social responsibility, which takes proactivity as the highest level of social responsibility. Contrary to Brown et al.'s (2005) suggestion, an ethical leader is not only a moral person and a moral manager who demonstrates what is normatively appropriate behavior and follows the current ethical norms. An ethical leader is also a moral entrepreneur who creates new ethical norms. This paper will therefore explore the relevant antecedents and outcomes of this new component of ethical leadership. I propose that new moral issues for which there is either no or inadequate morality create the need and room for moral entrepreneurship, and that once established, moral entrepreneurship contributes to the development of both society and the trust of stakeholders. This paper will also explore the avenues of empirical and normative research that this new component of ethical leadership opens up. As the backdrop to this discussion, we now turn our attention to the development and use of Brown et al.'s definition of ethical leadership.

\section{Current Definition of Ethical Leadership}

The concept of ethical leadership is also known by other names: ethical leader behavior (Kalshoven et al. 2011b), leadership ethics (Ciulla 1995), moralized leadership (Fehr et al. 2015), responsible leadership (Voegtlin et al. 2012), and managerial ethical leadership (Enderle 1987). The growing scholarly interest in this topic has been strongly influenced by the work of Brown and Treviño, who used a social-scientific empirical-descriptive approach to define ethical leadership (Treviño et al. 2000, 2003), to develop a scale for measuring it (Brown et al. 2005), and to propose new directions for future research into the antecedents and outcomes of ethical leadership (Brown and Treviño 2006; Brown and Mitchell 2010). This is not to suggest that the concept of ethical leadership has not received any scholarly attention prior to this. This concept was already being examined from both the normative and philosophical perspectives, and some scholars have suggested principles for actions that leaders should adopt. For example, Ciulla (1995) argued that respect for the rights and dignity of others is an essential feature of ethical leadership, whereas Kanungo and Mendonca (1996) emphasized altruism as characteristic of ethical leadership. Other leadership topics, such as transformational leadership (Burns 1978) and authentic leadership (Avolio et al. 2004), also took ethics into account. This is because ethics lies at the heart of leadership (Ciulla 1998); it is the central task of leadership (Arjoon 2000).

Brown et al. (2005, p. 120) used social learning theory to understand why ethical leadership is important to employees and how it works:

Ethical leaders are models of ethical conduct who become the targets of identification and emulation for followers. For leaders to be perceived as ethical leaders and to influence ethics-related outcomes, they must be perceived as attractive, credible, and legitimate. They do this by engaging in behavior that is seen as normatively appropriate (e.g., openness and honesty) and motivated by altruism (e.g., treating employees fairly and considerately). Ethical leaders must also gain followers' attention to the ethics message by engaging in explicit ethics-related communication and by using reinforcement to support the ethics message.

Thus, for Brown et al., ethical leadership is about leaders who are perceived as ethical by their followers. Managers become ethical leaders, firstly, by being and behaving ethically, that is, by fulfilling the role of "moral person"; and, secondly, by promoting the ethical behavior of others through two-way communication, reinforcement, and decision-making, that is, by fulfilling the role of "moral manager" (see also Treviño et al. 2000).

Based on this definition, Brown et al. (2005) developed the Ethical Leadership Scale (ELS) to measure perceptions of ethical leadership. They established an initial pool of 48 items of ethical leadership using the results from an earlier qualitative study by Treviño et al. $(2000,2003)$. The latter study requested 20 senior executives and 20 ethics officers from large US companies to think of an ethical leader at the executive level with whom they were familiar and to answer broad questions about the characteristics, behaviors, and motives they associated with that leader. Brown et al. subsequently conducted 20 in-depth interviews with MBA students from two universities to check the adequacy of their deductive approach to item generation. They asked interviewees to describe a supervisor whom they regarded as an ethical leader. Next, they conducted a survey consisting of 48 items among 154 MBA students. The exploratory factor analysis resulted in 21 items. They then consulted a construct-development expert who evaluated the measure's adequacy in terms of content and then eliminated 11 items that were potentially confusing or were worded in a manner that rendered them redundant. The resulting items were: "Listens to what employees have to say," "Disciplines employees who violate ethical 
standards," "Conducts his/her personal life in an ethical manner," "Has the best interests of employees in mind," "Makes fair and balanced decisions," "Can be trusted," "Discusses business ethics or values with employees," "Sets an example of how to do things the right way in terms of ethics," "Defines success not just by results but also by the way that they are obtained," and "When making decisions, asks "what is the right thing to do?"

\section{Supporters}

As mentioned above, the majority of empirical studies on ethical leadership adopt the definition of Brown et al. (2005). Although those who use this definition do so mostly without giving any justification, there are several possible explanations for its broad use. The definition is ethics-specific, it is clearly and succinctly formulated, and it elegantly draws a distinction between two components (i.e., moral person and moral manager) that each consists of multiple aspects (i.e., behavior and intention, and communication, reinforcement, and decision-making, respectively). Furthermore, the definition is flexible. The term "normatively appropriate" is kept deliberately vague because "what is deemed appropriate behavior is somewhat context dependent" (Brown et al. 2005, p. 120). There are at least two studies that justify their use of the Brown et al. definition: Rubin et al. (2010) explicitly appreciate Brown et al.'s definition because it places ethical leadership at the nexus of positive forms of leadership, and Mayer et al. (2009, p. 1) appreciate the definition for its "sole and explicit focus on the ethical aspect of leadership."

Many scholars employ the Ethical Leadership Scale (ELS): Toor and Ofori (2009), Avey et al. (2011), Chughtai et al. (2015), DeConinck (2015), and Wu et al. (2015), to name some. Walumbwa and Schaubroeck (2009) and Mayer et al. (2012) also used ELS but excluded one item. In the case of the former, more than half of the respondents declined to respond to that item (i.e., "conducts his or her personal life in an ethical manner"). In the case of the latter, the item overlapped with another scale that was being used. Some possible explanations for the widespread use of ELS are thus: it has been tested extensively, it has nomological and discriminant validity, and it consists of a small set of items, which makes it easy to administer and combine with other scales.

\section{Criticisms}

Despite its wide use, Brown et al.'s (2005) definition and scale have elicited some criticisms from scholars, such as Eisenbeiß (2012), Voegtlin et al. (2012), Yukl et al. (2013), and Fehr et al. (2015). There are four points to the critique.
The first is that the concept of ethical leadership by Brown et al. (2005) is only descriptive. Voegtlin et al. (2012, p. 4) points out that the Brown et al. approach to ethical leadership remains largely descriptive because, "By only describing prevailing moral norms, they do not allow for a critical justification of what is ethically correct." This implies that common sense is the only actual benchmark for what is ethically right, and therefore it cannot provide ethical orientation for leaders. Eisenbeiß (2012) holds the same view. She finds Brown et al.'s definition of ethical leadership too vague (i.e., it does not specify any particular norm to which ethical leaders can refer) and their approach too Western-based (i.e., it fails to consider viewpoints, principles, or values from other cultural perspectives). As a matter of fact, the Brown et al. definition and its original list of items for the ethical leadership scale were indeed based on the limited input from only 20 ethics officers and 20 senior executives from large US organizations, who were asked about their current ideas and expectations of ethical leadership.

A second point of critique is the incompleteness of the definition and scale of the moral person and moral manager. Fehr et al. (2015) find that ethical leadership researchers have downplayed the role of other, less studied elements of morality, such as purity and loyalty. The current "focus on only a narrow slice of the moral domain provides an unstable foundation on which to build a comprehensive theory of ethical leadership" (Fehr et al. 2015, p. 182). As a result, they warn that scholars risk "overlooking issues that are of prime moral importance to many individuals throughout the world, developing an oversimplified view of what it means to be an ethical leader, and only acknowledging a subset of the behaviors that ethical leadership might encourage" (Fehr et al. 2015, p. 183). The focus is thus too much on the interpersonal component of leadership rather than on analyzing how ethical leaders set ethical goals (Eisenbeiß 2012). Yukl et al. (2013) are also skeptical. They consider Brown et al.'s scale of ethical leadership (ELS) lacking some relevant aspects of ethical leadership, such as honest communication, behavior consistent with espoused values, and fair allocation of assignments and rewards.

A third criticism is that some items are not characteristic of ethics. Yukl et al. (2013) point out that ELS not only lacks some items but that some of the included items are not directly relevant to ethical leadership. In their view, the items "listens to what employees have to say" and "has the best interests of employees in mind" are not characteristic of ethical leadership. Brown et al. (2005) themselves admitted that these two items were more representative of the consideration-oriented leadership style than of ethical leadership, but they nevertheless retained both items in their scale without justification. Yukl 
et al. developed an adjusted scale consisting of 15 items that included, among others, honesty, integrity, fairness, altruism, consistency of behaviors with espoused values, communication of ethical values, and providing ethical guidance.

A final critique is that the scale is not multidimensional. Some scholars have argued that ethical leadership is a multidimensional construct. In opposition to ELS, Resick et al. (2006) proposed and tested four dimensions of ethical leadership, namely character and integrity, altruism, collective motivation, and encouragement. Kalshoven et al. (2011b) also developed a multidimensional scale of ethical leadership consisting of 38 items across the dimensions of fairness, integrity, ethical guidance, people orientation, power sharing, role clarification, and concern for sustainability. Yukl et al. (2013), however, criticized the scale of Kalshoven et al., pointing out that the subscales of clarification, power sharing, and people orientation are not inherently ethical and that the subscale of sustainability lacks many social issues that leaders may elect to endorse, such as democracy, free speech, global health, free enterprise, animal rights, and world peace.

\section{Toward a New Component of Ethical Leadership}

Suppose we either refute or accept the above criticisms. Would Brown et al.'s (2005) definition and scale of ethical leadership then still be valid? I believe that, either way, there would still be at least one component missing. This is the component of moral entrepreneurship whereby an ethical leader creates a new ethical norm.

According to Brown et al.'s (2005) definition of ethical leadership, leaders display normatively appropriate conduct. Examples of such conduct include openness and honesty, and treating employees fairly and considerately. For Brown et al., ethical conduct is conduct that is considered to be normatively appropriate. They suggest that ethical leadership is consistent with what a particular society or culture defines as right or wrong or as good or evil. They note, "For example, in some cultures normatively appropriate behavior might include speaking out publicly against some organizational action; in other cultures, such public voice would be considered to be normatively inappropriate" (Brown et al. 2005, p. 120). This corresponds with how Treviño and Nelson (2010, p. 19) define ethics, i.e., as "behavior that is consistent with the principles, norms, and standards of business practice that have been agreed upon by society." However, this is not leadership in the sense of leading ethics. The literature on corporate social responsibility can provide arguments for what this means.
In addition to social learning theory, which focuses on why and how supporters follow a leader, a social development approach to the concept of ethical leadership is also needed because it focuses on the direction that leadership should take. Studies on corporate social responsibility are concerned with how companies can contribute to societal development, not only in the sense of solving social problems (Davis and Blomstrom 1975) but also in the sense of improving social welfare, promoting social progress, and creating new social value (Fang et al. 2010). According to Carroll's (1979) widely used typology, there are four kinds of strategies that companies can follow to contribute to the development of society: obstructionist, defensive, accommodative, and proactive. These strategies are situated in a continuum, from doing nothing to doing much. The difference between an accommodative and proactive strategy is that companies that adopt an accommodative strategy meet stakeholder's demands without initiating voluntary actions for the common good, whereas companies with a proactive strategy initiate voluntary actions for the common good, and they lead the sector or industry. Thus, being proactive coincides with the highest level of social responsibility. It is only at this level, according to Carroll, that leadership takes place.

The literature on leadership also discusses proactive leadership. Based on a literature review, Wu and Wang (2011) define proactive leadership as "generating and enacting self-initiated and future-focused leading actions that are persistently sustained to bring changes toward the environment" (2011, p. 305). In their view, proactive leadership requires leaders to do more than what is required and expected of them. This kind of leadership is also forward-looking, responsive to opportunities or challenges in advance rather than merely focusing on the problems or demands at hand. Such leaders actively set goals to create a better future. According to Bateman and Crant (1999), proactive leaders actively master their environment and effect environmental change. Proactive leaders are innovative: they realize innovation, defined as "the generation, acceptance, and implementation of new processes, products, or services for the first time" (Pierce and Delbecq 1977, p. 29).

The quality of proactiveness also distinguishes leadership from management. There are several definitions and interpretations of the difference between leadership and management (Bass 1981; Rost 1995), and in some cases they are used interchangeably (Dirks and Ferrin 2002). A crucial difference is that management concerns the implementation of what is set and what others expect, whereas leadership concerns, first and foremost, the setting of new standards and the formulation of new ambitions and goals (Bennis and Nanus 1985). Brown et al. (2005) also mention proactivity in relation to ethical leadership. They 
note that ethical leaders are proactive in that they set ethical standards and promote them among their followers: ethical leaders undertake "proactive efforts to influence followers" (2005, p. 597), and they are "proactive role models for ethical conduct" (2005, p. 597). However, if we apply Carroll's approach to ethical leadership, being proactive then goes one step further. Ethical leadership is not about following the consensus reached in society; this would simply be an accommodative strategy. Instead, ethical leadership leads ethics by creating new ethical norms and being innovative in ethics. It is therefore through leadership in ethics that ethical norms that are not yet generally accepted in society are established. Ethical leaders do not only challenge the norm, as Taffinder (1997) suggests, or rethink ethics, as Halse and Honey (2007) recommend, or reflect on ethical goals, as Voegtlin et al. (2012) propose. Ethical leaders also create new ethical norms, standards, principles, or values.

An example is the CEO who, based on the belief that once goods are delivered the money for it belongs to the supplier, decided to pay invoices immediately even though the norm in the sector then was to only pay suppliers after 90 days, and this was an expensive measure because there were no supplier discounts for paying quicker. Other examples are the manager who, out of respect for animals, led his airline company to be the first to introduce a ban on the transport of dead animals as yacht trophies; the lingerie shop manager who, out of respect for women, made his shop the first in his country to stop portraying sparsely dressed women on advertising billboards; and the manager who, out of respect for the stakeholders, established in his organization the new norm that employees should prevent not only conflicts of interest but also the appearance of it. Creating new ethical norms is what Paine (2003, p. 246) hints at when she calls on leaders to "break through the thought systems of old orthodoxies." This resonates too with Schein's (2010, p. 2) definition of leadership as "the ability to step outside the culture to start evolutionary change processes." Contrary to Lawton and Páez's (2015) view, ethical leadership is not only about being bound by convention; it is also about developing new and better conventions.

\section{The Moral Entrepreneur}

In the sociological literature, someone who creates a new ethical norm is called a moral entrepreneur. Becker coined this term in 1963 to explain how moral reforms take place (Adut 2004). Becker's (1963) central thesis is that social groups create deviance by making the rules whose infraction constitutes deviance and then applying those rules to those people who deviate and labeling them as outsiders. For Becker, moral entrepreneurs are those people who make this moral reform happen. He differentiates between two kinds of moral entrepreneurs: those who create new norms and those who enforce these new norms. The crusading reformer, as rule-creator, is the moral entrepreneur par excellence. The moral entrepreneur experiences some evil that profoundly disturbs him and that he wants to correct by translating a preferred norm into legal prohibitions; however, he also risks becoming an outsider himself when he is not successful in his attempt to create support for the new rule or norm.

The concept of moral entrepreneurship, or what Sunstein (1996) calls norm entrepreneurship, has been applied to the challenges faced by nongovernmental organizations concerned with human rights (Felner 2012), to the conditions under which global norms become part of the agenda of global governance (Reich 2003), to the transformation and institutionalization of international commercial arbitration as the leading contractual method for the resolution of transnational commercial disputes (Dezalay and Garth 1995), and to kitchen television programs that tackle some social problems like health and social exclusion (Hollows and Jones 2010). Fishman (2014) analyzed four examples of moral entrepreneurship: the incubation of moral norms against smoking, drunk driving, underage drinking, and copyright infringement. Yurtsever (2003) developed a moral entrepreneurial personality scale. He thinks moral entrepreneurs "may break existing moral codes and cause a new form of rule to develop" (p. 3), sometimes even at a risk to life and limb.

The concept of moral entrepreneurship has been applied to the business field, although not in relation to the topic of ethical leadership. Fuller (2013), who analyzed the careers of three exemplars of the moral entrepreneur (i.e., Robert McNamara, George Soros, and Jeffrey Sachs), thinks of moral entrepreneurship as the fine art of recycling evil into good. What makes moral entrepreneurs so entrepreneurial is that "they alter not only our sense of which persons or actions are 'right' or 'wrong', 'good' or 'evil' but also what those very terms mean" (Fuller 2013, p. 122). Wrage and Wrage (2005) applied the concept of moral entrepreneurs to multinational enterprises fighting against corruption in regimes where corruption is pervasive. Smith and Carroll (1984) also note the usefulness of the concept of moral entrepreneurship in explaining why employees who observe wrongdoing speak up to correct the wrongdoing or wrongdoers.

The moral entrepreneur who creates a new normgradually or suddenly, formally or informally, within and/ or outside an organization-should not be confused with the social entrepreneur. Whereas social entrepreneurs can be agents of change and emphasize innovation (Nicholls and Cho 2008), they do not necessarily introduce new ethical norms. Likewise, a moral entrepreneur, as an 
innovator in ethics, should not be confused with the ethical innovator (Schumacher and Wasieleski 2013), who innovates in a normatively appropriate way. Also, moral entrepreneurship is neither what Anderson and Smith (2007) call the morality of entrepreneurship, which is the values and behaviors associated with being enterprising, nor what Hargreaves (2004) defines as the creation of an account of the organization in moral terms.

The component of moral entrepreneurship complements the two other components of ethical leadership (i.e., moral person and moral manager) because it highlights the creation of new norms instead of "only" following and implementing current ethical norms. Whereas the moral person is oriented toward who the leader is and the moral manager toward how the leader influences others, the moral entrepreneur is focused on what norms to establish. At the same time, the moral person and moral manager components, in their turn, complement the moral entrepreneur component. The concept of the moral person focuses on, for example, the motivation of the ethical leader, which, as Wrage and Wrage (2005) suggest, is not part of the concept of the moral entrepreneur but which may make the entrepreneur successful in his attempt to create a new norm and get others to follow it. Becker (1963) suggests that the humanitarian motive of helping others is important for a moral entrepreneur. Yurtsever (2003), in developing a scale for moral entrepreneurship personality, suggests that moral entrepreneurs demonstrate high moral virtues, such as justice and honesty. Moreover, being a moral manager is important to be able to get the support of others to follow the new ethical norm. The task of implementing a new norm could, as Becker (1963) argues, also be done by someone else: by the rule- or norm enforcer. At the same time, to be successful as a norm creator, one should get the support of others oneself. In the case of moral entrepreneurship, this requires the moral manager. Although these three components of ethical leadership complement each other, it is still possible for someone to exhibit only one or two of them. This makes ethical leadership a multidimensional construct. For instance, one can be a moral entrepreneur without being a moral manager (what Becker calls the norm creator); or one can be a moral manager without being a moral entrepreneur (what Becker calls the norm enforcer).

The concept of moral entrepreneurship does not suggest that a leader creates new ethical norms for all issues that he faces. A leader can display moral entrepreneurship regarding one issue while he is reactive in relation to another. This corresponds with Carroll's (1979) view of corporate social responsibility strategies. According to Carroll, organizations can adopt different strategies toward various social issues like consumerism, discrimination, and safety. Carroll proposes that organizations adopt a corporate social responsibility cube so they can plot their strategy for different issues on a case-to-case basis. A moral entrepreneur is therefore issue-specific.

The plea to include moral entrepreneurship as a third component to the current approach on ethical leadership implies that all the three components should be considered as jointly necessary conditions for ethical leadership. One who does not create a new norm but complies with existing ethical norms and stimulates others to follow them is a moral person and a moral manager but not an ethical leader. This is not problematic because ethical leadership is not a moral obligation for everyone, not even for every manager. Ethical leadership or being an ethical leader depends on, for example, the opportunities for moral entrepreneurship (we will explore this in the next section). So being "only" both a moral person and a moral manager does not make someone unethical. It might even be praiseworthy to be only a moral person and a moral manager when, for example, the first priority is to ensure that everyone, including oneself, follows the current moral norms. However, we can still speak of ethical leadership even if no new norm is created. This is the case when someone is already a leader on other grounds (being for example a leader in strategy or product development) and where the adjective "ethical" means that this person leads in an ethical way (being a moral person and moral manager). Here we can speak of leadership with ethics but not leadership in ethics. In the former someone is already a leader, and in the latter someone becomes a leader because he leads ethics. There is still a difference even if we use the same term, "ethical leader" (or "ethical leadership"), to refer to both meanings. In the first case, the stress is on "leader": the leader is ethical. In the second case, the stress is on "ethical": that which is ethical makes the leader a leader.

A possible reason why the creation of new ethical norms is not included in Brown et al.'s (2005) definition of ethical leadership is the context within which the increasing academic attention to ethical leadership has taken place. This context is marked by two crises: the dot-com crisis involving several accountancy frauds at the start of this century, and the financial-economic crisis that started toward the end of the first decade of this century. Many publications on ethical leadership, such as Treviño et al. (2003), Brown et al. (2005), Brown and Treviño (2006, 2014), Walumbwa and Schaubroeck (2009), Kalshoven et al. (2011b), Eisenbeiß and Giessner (2012), Yukl et al. (2013), and Bedi et al. (2016), start with references to the business scandals and hold these up as a reason for studying and improving ethical leadership. These scandals illustrate that prevailing norms were violated. This fact indeed raises questions about how leaders can improve compliance with these norms and about their role in 
stimulating their followers to also comply with these norms. Society would certainly be better off if business leaders set an example and promote what is normatively appropriate. However, even if there were no such scandals, ethical leadership in terms of moral entrepreneurship would still be relevant because, as we will explore in the next section, new issues arise that require new ethical norms.

\section{A Model of Moral Entrepreneurship}

In a meta-analysis using Brown et al.'s (2005) definition of ethical leadership, Bedi et al. (2016) identify 20 significant outcomes of ethical leadership. A number of these outcomes, along with antecedents that have been found in other studies on ethical leadership, can also be applied to moral entrepreneurship given that the mechanism of social learning plays a role here, too. For example, Brown and Treviño's (2014) finding that ethical role models positively influence managers to become moral persons and moral managers also holds for moral entrepreneurs. Individuals who have been exposed to a moral entrepreneur are more likely to become a moral entrepreneur themselves because they have experienced its potential and attraction and how it is done. The positive outcomes of ethical leadership that Bedi et al. (2016) observed (such as job satisfaction, commitment, organizational citizenship behavior, job performance, job engagement, and organizational identification), together with the negative outcomes (such as turnover intentions, counterproductive work behavior, and relationship conflict) could also apply, whether stronger or weaker, to moral entrepreneurship. This is because followers of moral entrepreneurs are likely to feel more stimulated and inspired, which improves their behavior and well-being. In addition, because the concept of moral entrepreneurship differs from the other two components, it introduces other antecedents and outcomes of ethical leadership. In this paper, I highlight eight antecedents and two outcomes (see Fig. 1) that are not or are differently recognized in the current literature on ethical leadership. (Note that I am not claiming that none of these antecedents and outcomes hold as well for the two other components of ethical leadership.)

\section{Antecedents}

\section{Opportunity for Moral Entrepreneurship: Moral Issues and Moral Void}

The opportunity for moral entrepreneurship can differ from what has been proposed in the case of the two other components of ethical leadership (i.e., the moral person and the moral manager). Brown et al. (2005) recognized the important role that context plays in ethical leadership. In their definition, ethical leadership amounts to adhering to prevailing moral norms. However, the number of existing norms that need to be adopted and implemented by leaders does not determine moral entrepreneurship. The more moral issues there are for which there are no applicable or adequate moral norms, the more opportunities there will be for moral entrepreneurship, and the more likely moral entrepreneurship will arise.

Moral entrepreneurship depends on whether there are moral issues that need to be addressed or that will arise in the short or long term. These moral issues, whether they are problems, dilemmas, or challenges, are conditions for or enablers of societal improvement and development. If everything were and remained perfect, there would be no need to develop new ethical norms. For this reason, Carroll (2000) wrote about the new ethical challenges for business that would come with the new developments of this century. It is not only the number of moral issues that creates room for moral entrepreneurship but also their urgency. The urgency of an issue is its magnitude in terms of potential harm and its proximity in time and space (Butterfield et al. 2000). The more urgent an issue, the more morality or an appropriate normative response is required (cf. Jones 1991). According to social learning theory, situations that have the potential to cause great harm are likely to be socially salient and to focus an observer's attention, which in turn raises the probability of an immediate response (Brown and Treviño 2006). For Finnemore and Sikkink (1998), moral entrepreneurs are critical for norm emergence because they call attention to issues or even create them.

As mentioned earlier, moral entrepreneurship is required only if morality is lacking or inadequate with respect to a particular issue; in other words, if there is a moral void. For the purpose of this paper, I define moral void as the absence of a shared and adequate moral orientation. This definition is slightly different from Voegtlin et al.'s (2012) use of the term as a loss of shared moral orientation. A moral vacuum is not dependent on the loss of a shared moral orientation; it can also result from a new issue arising. A moral void is therefore also not immoral per se (Carroll 2000). Immorality implies a violation of some moral standards, whereas a moral void means that there is no applicable moral standard at all (yet). A moral void also differs from what Donaldson and Dunfee (1994) call moral free space. A moral free space presupposes that there are (generally known) spaces where or matters over which people are free to define moral norms for themselves. A moral void can also exist without anyone knowing of its existence, and it does not imply a complete lack of moral expectations regarding a particular issue. Ideas about what 


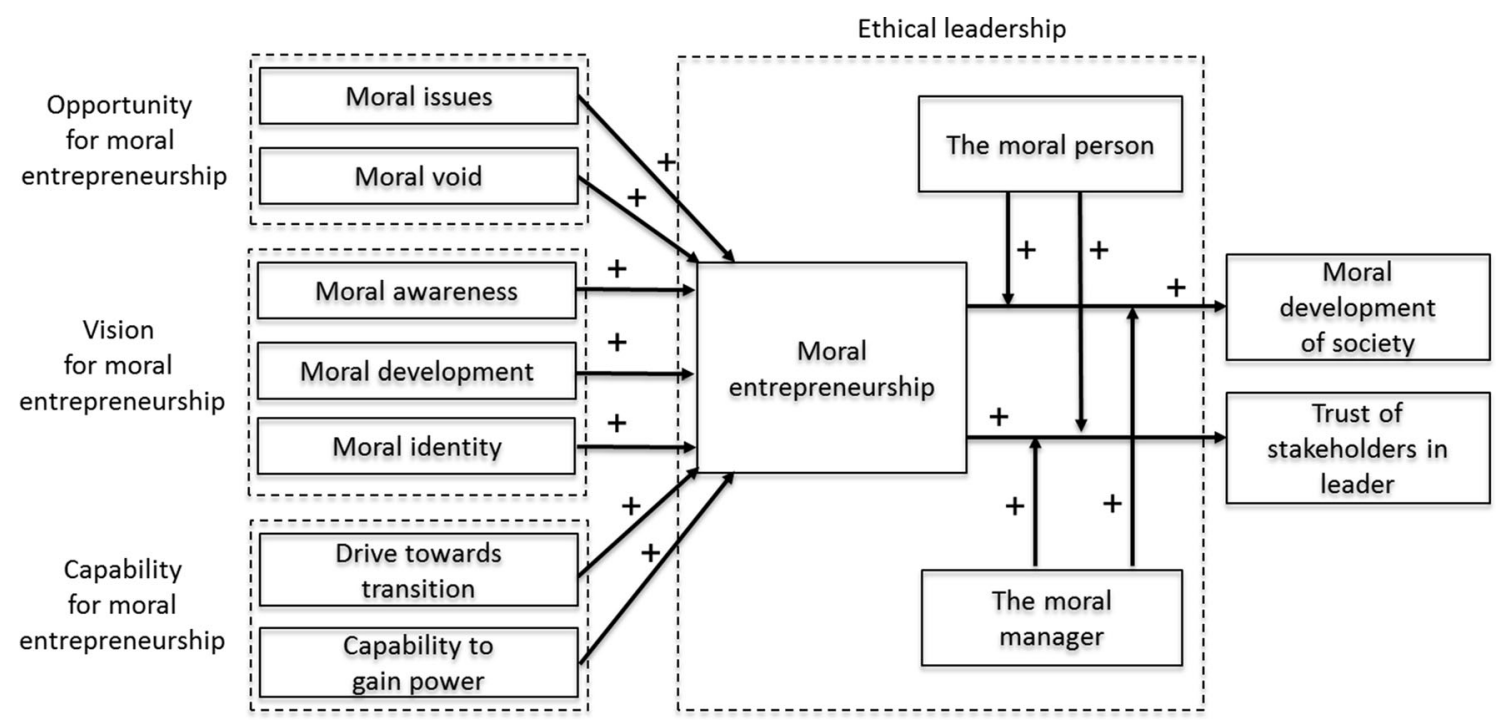

Fig. 1 A model for moral entrepreneurship

would be ethical can already exist, but as long as there is no crystalized norm of what is ethical about the particular issue in question, one can then speak of some sort of moral void that needs to be filled.

Moral consensus, defined as the existence of strong ethical norms in a given situation, is an important condition for ethical leadership with respect to the moral manager and moral person (Brown and Treviño 2006). However, it is precisely the absence of moral consensus that creates room for moral entrepreneurship. We can say the same about the argument of Campbell (2007) and Carroll and Shabana (2010) that the higher the normative expectations and the stronger the calls from stakeholders in relation to organizations, the higher the level of corporate social responsibility that follows. Again, precisely the opposite applies in the case of moral entrepreneurship: the lower the normative expectations and the weaker the calls of stakeholders, the more likely it is for moral entrepreneurship to arise. For this reason, it is the moral entrepreneur who has to create attention and expectations: by creating a scandal (Adut 2004), moral panic (Hunt 1997), or a value crisis (Fuller 2013). The same holds for the complexity of the organizational environment: i.e., it is negatively related to ethical leadership in terms of the moral manager and the moral person because the likelihood of ethical dilemmas increases in more complex environments (Eisenbeiß and Giessner 2012). In the case of moral entrepreneurship, the opposite is true: complex situations are likely to generate dilemmas that require new norms through which moral entrepreneurship becomes more needed and, ceteris paribus, more likely. To conclude, with regard the opportunity for moral entrepreneurship, the propositions are as follows:
Proposition 1a Moral issues have a positive influence on the likelihood of moral entrepreneurship.

Proposition 1b Moral void has a positive influence on the likelihood of moral entrepreneurship.

Vision on Moral Entrepreneurship: Moral Awareness, Moral Development, and Moral Identity

According to Rest (1986), the identification of moral issues is the first stage of the ethical decision-making process. Brown et al. (2005) argue that moral awareness-the recognition of the moral aspects of a given situation-is essential for ethical leadership. It is not only relevant that moral entrepreneurs recognize the moral dimensions of a given issue; they should also recognize that an issue is (potentially) arising. For Yurtsever (2003), the process of anticipating moral issues is clearly critical to the success of moral entrepreneurs: they have an image of the future of a society, including what will happen and what might happen. Moral entrepreneurs may show their leadership in situations where others have not yet recognized an issue, or where the issue is still at a very early stage of development, or where it has not yet manifested itself. Moral entrepreneurs have the moral awareness or sensitivity to recognize moral issues as such. So the more morally aware a person is, the more he is likely to be a moral entrepreneur.

The next stage of the ethical decision-making process is moral judgment (Rest 1986). How the leader comes to a new ethical norm after recognizing a moral issue is crucial for moral entrepreneurship. Moral entrepreneurs have an image not only of what will happen and what might happen 
but also of what ought to happen (Yurtsever 2003). Brown and Treviño (2006) use Kohlberg's (1969) theory of cognitive moral development to argue that a leader's level of moral reasoning is positively related to ethical leadership. Jordan et al. (2013) found empirical evidence for this claim. We expect the same relationship for moral entrepreneurship, albeit even stronger. Following Kohlberg's three levels of moral development, moral entrepreneurship would then be negatively related to the second level (where leaders follow the moral conventions in their environment) given that moral entrepreneurship does not take place in situations of conformity. Barker's (2001) view of leadership as a deviation from convention also suggests this idea. Leaders at the third level of moral development are expected to have a positive and stronger relationship with moral entrepreneurship because at this postconventional level, leaders base their arguments on principles that they believe are right and good for society. This corresponds with Eisenbeiß's argument that ethical leaders are especially likely to emerge at the highest level of moral development when they "truly widen their perspective of society and environment and start thinking in global terms" (2012, p. 799). Thus, the distinction between levels two and three of Kohlberg's moral development model is crucial for the distinction between the moral person and the moral entrepreneur.

Hence, we expect moral awareness and moral development to foster moral entrepreneurship. However, where there is an abundance of moral issues for which there is no or inadequate morality, moral entrepreneurship does not require that a leader shows leadership on all those issues. The issue(s) to which a leader decides to commit is likely to depend on his moral identity, understood as an individual's "self-conception around a set of moral traits" (Aquino and Reed 2002, p. 1424). Aquino and Reed propose that moral identity is a self-regulatory mechanism that influences ethical behavior and is rooted in an individual's internalized notions of right and wrong. Moral identity has been associated with ethical leadership. For example, Mayer et al. (2012) found that leaders who regard their moral identity as highly important act in ways that are consistent with common understandings of what it means to be a moral person. However, we can also expect moral identity to be relevant in the selection of new issues and in the conversion to new norms. Scholars such as Aquino and Reed (2002) have argued that people differ in the degree to which they experience moral identity as being central to their overall self-definition. Nevertheless, we can also argue that specific traits of a person's identity may be related to the specific issues with regard to which they will choose to demonstrate moral entrepreneurship. For example, one whose moral identity is linked to caring for the natural environment is more likely to select issue(s) and norms in that area than someone who identifies with being a good employer or fair competitor. Thus, following Eisenbeiß's (2012) argument that moral identity helps to explain why leaders spend resources on addressing ethical dilemmas, we can conclude that moral identity also explains which dilemmas and issues leaders choose to engage in and spend resources on. Dezalay and Garth (1995) found in this respect that commercial arbitrators who are moral entrepreneurs are persons with strong moral beliefs.

In sum, the following three factors (stated in the form of propositions) are expected to influence the process by which moral issues are converted to new ethical norms.

Proposition 2a Moral awareness has a positive influence on the likelihood of moral entrepreneurship.

Proposition 2b Moral development has a positive influence on the likelihood of moral entrepreneurship.

Proposition 2c Moral identity has a positive influence on the likelihood of moral entrepreneurship.

\section{Capability for Moral Entrepreneurship: Drive Toward Transition and Capability to Gain Power}

Together with the opportunity to set a new norm and the vision to come to this new norm, ethical leadership also requires encouraging others to follow this new norm. Two important factors that are relevant for moral entrepreneurship but not recognized in the current literature on ethical leadership are related to the leader's capability for moral entrepreneurship: the drive toward transition and the capability to gain power.

A salient feature of moral entrepreneurship is that those leaders who practice it are the frontrunners in ethics. Moral entrepreneurship coincides with transitional leadership (cf. Smith 1993; Starratt 1999) in the sense that, contrary to Brown et al.'s (2005) view, these leaders are not focused on improving current practices to catch up with current ethical norms; rather they are focused on improving current ethical norms through the introduction of new and better ones. An antecedent of moral entrepreneurship is thus the extent to which a leader is driven toward transition, i.e., toward focusing on improving one or more ethical norms. This drive is important because improving ethics is a struggle accompanied by conflict and resistance (Kaptein 2017). The literature on moral entrepreneurship recognizes this drive. Becker (1963) notes that the prototype of the moral entrepreneur is the crusading reformer who is fervent and devoted. Yurtsever (2003) discovered the importance of physical and intellectual resistance in dedicating one's energy to moral issues and in pursuing desirable ends. Fuller (2013) finds that having a progressive mentality is crucial for moral entrepreneurs because they face risks. 
Nadelmann (1990) describes moral entrepreneurs as engaging in moral proselytism. Smith and Carroll (1984) consider moral entrepreneurs as men of conscience, the opposite of cowards who remain silent when they ought to speak. Therefore, the commitment and dedication of a leader is important. Bateman and Crant's study (1999) of proactive leaders, which show that perseverance is cardinal, supports this claim. Thus, the presence of a deeply rooted drive to transition facilitates the successful practice of moral entrepreneurship.

In addition to a leader being driven to improve ethics, it is also important that the improvement is successful (Becker 1963). Moral entrepreneurship is successful when others adopt the new ethical norm, and those who do not adopt are then considered outsiders (Becker 1963). This puts forward the importance of moral entrepreneurs gathering support for their proposed new norm. It may be more difficult to gather support for a new norm than for an existing one. A new norm may require a bigger change from its followers, and more diverse and even opposing opinions about it may arise that might cause resistance. The relative success of the emergence, acceptance, and enforcement of new norms depends on "the presence of aggressive moral entrepreneurs in advocating norms and garnering broad-based support for them" (Reich 2003, p. 9). It is therefore crucial for moral entrepreneurs to gain power (cf. Finnemore and Sikkink 1998). There are many sources of social power in an organization, for instance referent power (French and Raven 1959). Yukl et al. (2008) developed a taxonomy of eleven tactics used to proactively influence others and to gain power: e.g., rational persuasion, exchange, and inspirational appeal. Uhl-Bien and Carsten (2007) are one of the few who touched upon the necessity for ethical leaders to gain power. Most research in the field of ethical leadership seems to assume that those who want to exhibit ethical leadership already have power because they are in a management position or are a general leader. This is what Brown et al. (2005) explicitly assumed. However, Uhl-Bien and Carsten arrived at the conclusion about the importance of gaining power in their studies on upward ethical leadership (where subordinates tried to change a manager's unethical behavior). Uhl-Bien and Carsten argue that because subordinates have either insufficient or no power, they must then learn to establish their personal power. This personal power is developed through relationships, reputation, credibility, networks, competence, information, leadership skills, and expertise. What is relevant for moral entrepreneurs is the extent to which they are capable of building their power and applying that power in a manner that gets others to adopt the new ethical norm. Furthermore, believing that one has the capability to gain power stimulates one to create a new norm because the belief makes the successful implementation of the norm more likely. Moral entrepreneurs can encourage issues to be placed on the agenda in various ways, for instance, through their use of the media, lobbying, and testimony (Keck and Sikkink 2014). This leads to the next propositions:

Proposition 3a The drive toward transition has a positive influence on the likelihood of moral entrepreneurship.

Proposition 3b The capability to gain power has a positive influence on the likelihood of moral entrepreneurship.

\section{Outcomes}

Apart from the many outcomes of ethical leadership suggested in the literature, the concept of moral entrepreneurship brings other possible outcomes into the spotlight such as the moral development of society and the trust of stakeholders. These outcomes are not yet fully recognized in the literature on ethical leadership. Although the moral person and moral manager components of ethical leadership may also directly influence the moral development of society and the trust of stakeholders, in this section, we will only explore how the moral entrepreneurship component may lead to these outcomes. This will be followed by an exploration of how the other two components, as moderators, influence the outcomes of moral entrepreneurship.

\section{Moral Development of Society}

Creating a new ethical norm is characteristic of moral entrepreneurship. A new norm is created because, as discussed above, once a better ethical norm is followed, it contributes to a better society. We could also relate Brown et al.'s (2005) definition of ethical leadership to the development of society. For example, Kalshoven et al. (2011b) and Eisenbeiß (2012) argue that ethical leadership fosters citizenship and prosocial behavior. However, these operationalizations of ethical leadership take current morality as given and do not adequately acknowledge that leaders contribute toward improving society by leading ethics. The moral entrepreneurship approach for understanding ethical leadership thus recognizes that leaders can contribute to the development of society at a different level. Leaders foster, what Nonet and Selznick (1978) call, the moral development of society: i.e., the development of new and better ethical norms for society (cf. Gustafson 2001). This idea corresponds with Becker's (1963) claim that moral entrepreneurs can reform society by changing public morality, and with Fuller's (2013) view that moral entrepreneurs alter the societal opinions on the meaning of right and wrong. Thus, the next proposition is: 
Proposition 4 Moral entrepreneurship has a positive influence on the moral development of society.

\section{Trust of Stakeholders}

Trust is "a psychological state comprising the intention to accept vulnerability based upon positive expectations of the intentions or behavior of another" (Rousseau et al. 1998 , p. 395). It is a widely researched outcome of leadership performance (Dirks and Ferrin 2002). Some scholars have studied the relationship between trust and ethical leadership (Brown et al. 2005; Den Hartog and De Hoogh 2009). Prior research has found that ethical leadership is positively related to followers' trust in the leader because leaders who keep promises and behave consistently can be relied upon to do and act as they say (Kalshoven et al. 2011b). The concept of moral entrepreneurship adds another reason why ethical leadership may result in trust and why, contrary to Bedi et al.'s (2016) meta-study, it is not only the perceptions of followers that are relevant. Moral entrepreneurship gives a strong signal that a person values ethics because he goes further than what is expected and thus beyond current morality. Moral entrepreneurship shows especially the good will of a person, which is the basis of trust (Baier 1986). Moral entrepreneurship also shows a person's abilities to develop a vision on moral entrepreneurship and his capabilities to establish the norm. Thus, moral entrepreneurship strengthens the conviction that a person will also behave ethically in the future (cf. Hosmer 1995).

Eisenbeiß (2012) argues that ethical leadership enhances the trust not only of employees but also of customers. Ethical leadership, and especially moral entrepreneurship, can also enhance the trust of other stakeholders because moral entrepreneurship shows the importance a person attaches to ethics. If the newly introduced ethical norm is a reflection of the moral identity of a person, then this norm is likely to strengthen the stakeholders' expectations that this person will continue to commit resources to relevant issues, norms, or interests that will be at stake in the future. Moral entrepreneurship can be useful especially when trust has to be repaired. As Kim et al. (2004) suggest, acting in a manner that exceeds expectations can restore positive expectations because it demonstrates that the person is intrinsically committed to act with benevolence and integrity (cf. Gillespie and Dietz 2009). This discussion leads to the following proposition:

Proposition 5 Moral entrepreneurship has a positive influence on the trust that stakeholders place upon the person who demonstrates this quality.

\section{Moderators}

The three components of ethical leadership are expected to complement each other, as described above. For the moral entrepreneur component, this means that it may be influenced directly by the two other components. For example, being a moral person and a moral manager may give someone more room to create a new norm because it is quite likely that current norms have already been adopted and implemented, and therefore, it is more opportune to go one step (or even a quantum leap) further. Being a moral person and a moral manager may also give a person more confidence to create a new norm. This is because it is very likely that he will be able to adopt and implement the new norm, thereby making moral entrepreneurship successful. We will neither focus here on the direct influence of the two components on moral entrepreneurship nor will we discuss whether and to what extent the three components share the same antecedents. For example, the capability to gain power may be relevant not only for the moral entrepreneur (Proposition 3b) but maybe also for the moral person and moral manager (although perhaps less significantly, as argued above). Our focus here is similar to Becker's (1963) discussion of the sequence of and relationship between the norm creator and the norm enforcer: i.e., the moderating role of the moral person and the moral manager on the outcomes of moral entrepreneurship.

The components of the moral person and the moral manager are expected to positively influence (at least) the outcomes of moral entrepreneurship described above. When someone creates a new ethical norm (the moral entrepreneur) and demonstrates this new norm in his behavior (the moral person), it is likely that others will follow suit because of the influence of role modeling (Brown and Treviño 2014). This may consequently increase the impact of moral entrepreneurship on the moral development of society: the more followers there are, the more support they may create in society for the new norm. It may also increase the trust of stakeholders in the moral entrepreneur: the more followers there are, the more people to pass on the moral entrepreneur's vision and capabilities to the stakeholders; thus, the more the latter will be convinced about the moral entrepreneur's trustworthiness. When the moral entrepreneur demonstrates the new norm through his own behavior, it shows his capability to apply his vision of moral entrepreneurship upon himself; this also fosters the stakeholders' trust in him (cf. Benjamin 1990; Dineen et al. 2006; Kalshoven et al. 2011a). The same argument holds for someone who creates a new norm (the moral entrepreneur) and creates the environment in which others are stimulated to follow the new norm (the moral 
manager). When this leads to more followers, it will increase both the support for the new norm in society and the trust of stakeholders in the moral entrepreneur. By creating such a stimulating environment, the moral entrepreneur also shows his capability to pass on his vision for moral entrepreneurship to others. This also fosters the stakeholders' trust in him (Dineen et al. 2006). The final propositions are:

Proposition 6a Being a moral person positively influences the relationship between moral entrepreneurship and the moral development of society.

Proposition 6b Being a moral person positively influences the relationship between moral entrepreneurship and the trust that stakeholders place upon the person who demonstrates this quality.

Proposition 6c Being a moral manager positively influences the relationship between moral entrepreneurship and the moral development of society.

Proposition 6d Being a moral manager positively influences the relationship between moral entrepreneurship and the trust that stakeholders place upon the person who demonstrates this quality.

\section{Discussion}

This paper has critically and constructively engaged with the widely used definition of ethical leadership developed by Brown et al. (2005). In addition to the two components of ethical leadership they advance-i.e., moral person and moral manager - this paper proposes a third one, namely the moral entrepreneur. Instead of just following current or accepted morality, ethical leaders also lead morality through the creation of new ethical norms. With the addition of this new component, we get an enriched concept of ethical leadership. We can then restate Brown et al.'s definition as "the demonstration of normatively appropriate and new conduct through personal actions and interpersonal relationships, and the promotion of such conduct to followers through two-way communication, reinforcement, and decision-making" (italics added).

This paper also explored the antecedents and outcomes of moral entrepreneurship that either have not been acknowledged yet or are understood differently in the current ethical leadership literature. The antecedents are: the number and urgency of moral issues and the extent to which each of these moral issues exists in a moral void, which can be seen as the opportunity for moral entrepreneurship; the moral awareness, moral development, and moral identity of the leader, which refer to the vision on moral entrepreneurship; and the leader's drive toward transition and capability to gain power, which refer to the capability for moral entrepreneurship. The two new outcomes of moral entrepreneurship are the moral development of society and the trust of stakeholders.

\section{Research Implications}

The concept of moral entrepreneurship opens the door to new empirical and normative research in the field of ethical leadership.

The moral entrepreneur, as a new component of ethical leadership, has to be operationalized into a subscale and tested, like in the case of the first two components. The currently accepted definition of ethical leadership by Brown et al. (2005) does not incorporate the notion of a leader creating a new ethical norm. This notion is neither considered as an aspect of ethical leadership (see e.g., Khuntia and Suar 2004; Resick et al. 2011; Fehr et al. 2015) nor included as an item in current scales (e.g., Brown et al. 2005; Kalshoven et al. 2011b; Yukl et al. 2013). Only the current ELS item "Sets an example of how to do things the right way in terms of ethics" can capture to some extent the notion of moral entrepreneurship. This is because setting an example of how to do things the right way could also imply creating new ethical norms. We can use the scale for general moral entrepreneurial personality developed by Yurtsever (2003) as a start. Future research would therefore have to identify the items that represent the moral entrepreneur in organizational settings and examine whether this component is one- or multidimensional and how this component is related to the other components of ethical leadership. This would hopefully make a stronger argument for the moral entrepreneur as a new component of ethical leadership.

Including the component of moral entrepreneurship in measuring ethical leadership offers the opportunity to redo previous empirical studies. As mentioned above, previous findings about the antecedents and outcomes using Brown et al.'s (2005) definition of ethical leadership could not be applied directly to this new component. Therefore, many of the studies on ethical leadership could be redone using the above-suggested new subscale for moral entrepreneurship. This may also yield stronger and weaker relationships with both the antecedents and outcomes of ethical leadership than what is currently the case; or the relationship might even be different. For example, Eisenbeiß and Giessner (2012) found that organizational culture is an antecedent of ethical leadership. However, if moral entrepreneurship is defined as changing the culture, as we did above, we can expect the opposite effect: if the organizational culture is lacking, then more moral entrepreneurship is needed, and therefore moral entrepreneurship may be more likely.

Apart from the empirical implications, there are also some theoretical implications. The ethical basis of moral 
entrepreneurship is that by creating new norms society develops. However, leaders are not unethical per se if they do not establish new ethical norms. Whether moral entrepreneurship is morally required or praiseworthy depends on the circumstances. We have touched on this issue by proposing the number and urgency of moral issues for which morality is lacking or inadequate as an antecedent of moral entrepreneurship. Future normative research could systematically study the factors that create the moral obligation for a leader to demonstrate moral entrepreneurship. One reason for doing this is to prevent moral entrepreneurship from being associated with producing moral saints (Wolf 1982) in organizations. More research is also needed to better understand the relationships between the three components of ethical leadership.

Future research could also focus on the normative operationalization of moral entrepreneurship. One of the criticisms against Brown et al.'s (2005) concept of ethical leadership is that it is only descriptive. The definition of moral entrepreneurship that this paper proposes is also descriptive because it leaves open the question when a norm can be considered new and better. Is a norm new if it is novel in a particular context, or if it has not existed in the world before? Moreover, to determine whether a new ethical norm is better than current morality, which perspective should we adopt: a deontological, virtue ethics, or a utilitarian perspective? The societal development concept proposed in this paper may provide a basis for determining to what extent a new norm contributes to societal development and thus could be called ethical. However, in order to provide such a basis, the concept of societal development needs to be further developed into a theory.

Future research might also explore whether and how moral entrepreneurship can be employed at levels other than the managerial one. The current focus of research on ethical leadership is largely, implicitly or explicitly, on managers, including CEOs (Wu et al. 2015), senior executives (Treviño et al. 2000, 2003), top management (Mayer et al. 2009), and lower-level management (Brown et al. 2005). As the literature on leadership generally acknowledges (Kotter 2007; Palmer 2009), leadership is not bound to a specific function or level. Therefore, an employee could also become a moral entrepreneur if that person creates a new ethical norm. Organizations and sectors can also demonstrate moral entrepreneurship. Just like the proactive social responsibility strategy of organizations that Carroll (1979) describes, organizations can have a proactive ethics strategy through which the organization can introduce new norms that others can follow. Only a few scholars, such as Wrage and Wrage (2005), have applied moral entrepreneurship to the organizational level.

\section{Implications for Management}

This paper makes an appeal to managers not only to comply with what is regarded as normatively appropriate and to encourage others to comply but also to explore whether there are opportunities to develop new ethical norms, to realize these opportunities when possible and desirable, and to get others to adopt these new norms. Much like the CEO of GlaxoSmithKline (GSK) who gave the following explanation for the company's decision in 2013 to stop financing doctors who speak at medical conferences about the results of the research they conducted for GSK: "It is patients' interests that always come first. We recognize that we have an important role to play in providing doctors with information about our medicines, but this must be done clearly, transparently and without any perception of conflict of interest" (GSK 2013). GSK was the first drug company to have this policy.

A moral entrepreneurship approach holds that management should not only follow ethics but should also lead ethics when there is opportunity for moral entrepreneurship. The model proposed in this paper offers suggestions for realizing moral entrepreneurship. Managers can start by being alert to current or potential moral issues for which an adequate morality has not yet been established. Next, managers can select one or more issues that reflect their own and their organization's moral identity so they can develop a new ethical norm on the basis of a vision of how and why the norm contributes to a better society. The next step would be for managers to commit to adhering to the norm and to generate support for this new norm. In the process of influencing others to adopt the norm, managers can monitor the outcomes to determine whether moral entrepreneurship indeed fosters the trust of stakeholders and promotes the moral development of society.

\section{Compliance with Ethical Standards}

Ethical Approval This article does not contain any studies by the author involving human participants or animals.

Open Access This article is distributed under the terms of the Creative Commons Attribution 4.0 International License (http://creative commons.org/licenses/by/4.0/), which permits unrestricted use, distribution, and reproduction in any medium, provided you give appropriate credit to the original author(s) and the source, provide a link to the Creative Commons license, and indicate if changes were made.

\section{References}

Adut, A. (2004). Scandal as norm entrepreneurship strategy: Corruption and the French investigating magistrates. Theory and Society, 33, 529-578. 
Anderson, A. R., \& Smith, R. (2007). The moral space in entrepreneurship: An exploration of ethical imperatives and the moral legitimacy of being enterprising. Entrepreneurship and Regional Development, 19, 479-497.

Aquino, K., \& Reed, A. I. (2002). The self-importance of moral identity. Journal of Personality and Social Psychology, 83, $1423-1440$.

Arjoon, S. (2000). Virtue theory as a dynamic theory of business. Journal of Business Ethics, 28, 159-178.

Avey, J. B., Palanski, M. E., \& Walumbwa, F. O. (2011). When leadership goes unnoticed: The moderating role of follower selfesteem on the relationship between ethical leadership and follower behavior. Journal of Business Ethics, 98, 573-582.

Avolio, B. J., Luthans, F., \& Walumbwa, F. O. (2004). Authentic leadership: Theory building for veritable sustained performance. The Gallup Leadership Institute: Lincoln.

Baier, A. (1986). Trust and antitrust. Ethics, 96, 231-260.

Barker, R. A. (2001). Leadership is deviation from convention: The nature of leadership. Human Relations, 54, 469-494.

Bass, B. M. (1981). Stogdill's handbook of leadership: A survey of theory and research. New York: Free press.

Bateman, T. S., \& Crant, J. M. (1999). Proactive behavior: Meaning, impact, recommendations. Business Horizons, 42(3), 63-70.

Becker, H. (1963). Outsiders: Studies in the sociology of deviance. New York: The Free Press of Glencoe.

Bedi, A., Alpaslan, C. M., \& Green, S. (2016). A meta-analytic review of ethical leadership outcomes and moderators. Journal of Business Ethics, 139, 517-536.

Benjamin, M. (1990). Splitting the difference: Compromise and integrity in ethics and politics. Kansas: University Press of Kansas.

Bennis, W., \& Nanus, B. (1985). Leaders: Strategies for taking charge. New York: Harper Collins.

Brown, M. E., \& Mitchell, M. S. (2010). Ethical and unethical leadership: Exploring new avenues for future research. Business Ethics Quarterly, 20, 583-616.

Brown, M. E., \& Treviño, L. K. (2006). Ethical leadership: A review and future directions. The Leadership Quarterly, 17, 595-616.

Brown, M. E., \& Treviño, L. K. (2014). Do role models matter? An investigation of role modeling as an antecedent of perceived ethical leadership. Journal of Business Ethics, 122, 587-598.

Brown, M. E., Treviño, L. K., \& Harrison, D. A. (2005). Ethical leadership: A social learning perspective for construct development and testing. Organizational Behavior and Human Decision Processes, 97, 117-134.

Burns, J. M. (1978). Leadership. New York: Harper \& Row.

Butterfield, K. D., Treviño, L. K., \& Weaver, G. R. (2000). Moral awareness in business organizations: Influences of issue-related and social context factors. Human Relations, 53, 981-1018.

Campbell, J. L. (2007). Why would corporations behave in socially responsible ways? An institutional theory of corporate social responsibility. Academy of Management Review, 32, 946-967.

Carroll, A. B. (1979). A three-dimensional conceptual model of corporate performance. Academy of Management Review, 4, 497-505.

Carroll, A. B. (2000). Ethical challenges for business in the new millennium: Corporate social responsibility and models of management morality. Business Ethics Quarterly, 10, 33-42.

Carroll, A. B., \& Shabana, K. M. (2010). The business case for corporate social responsibility: A review of concepts, research and practice. International Journal of Management Reviews, 12, $85-105$.

Chughtai, A., Byrne, M., \& Flood, B. (2015). Linking ethical leadership to employee well-being: The role of trust in supervisor. Journal of Business Ethics, 128, 653-663.
Ciulla, J. B. (1995). Leadership ethics: Mapping the territory. Business Ethics Quarterly, 5, 5-28.

Ciulla, J. B. (1998). Ethics: The heart of leadership. Westport: Praeger.

Davis, K., \& Blomstrom, R. L. (1975). Business and society: Environment and responsibility. New York: McGraw-Hill.

DeConinck, J. B. (2015). Outcomes of ethical leadership among salespeople. Journal of Business Research, 68, 1086-1093.

Den Hartog, D. N. (2015). Ethical leadership. Annual Review Organizational Psychology and Organizational Behavior, 2, 409-434.

Den Hartog, D. N., \& De Hoogh, A. H. B. (2009). Empowering behaviour and leader fairness and integrity: Studying perceptions of ethical leader behaviour from a levels-of-analysis perspective. European Journal of Work and Organizational Psychology, 18, 199-230.

Dezalay, Y., \& Garth, B. (1995). Merchants of law as moral entrepreneurs: Constructing international justice from the competition for transnational business disputes. Law and Society Review, 29, 27-64.

Dineen, B. R., Lewicki, R. J., \& Tomlinson, E. C. (2006). Supervisory guidance and behavioral integrity: Relationships with employee citizenship and deviant behavior. Journal of Applied Psychology, 91, 622-635.

Dirks, K. T., \& Ferrin, D. L. (2002). Trust in leadership: Metaanalytic findings and implications for research and practice. Journal of Applied Psychology, 87, 611-628.

Donaldson, T., \& Dunfee, T. W. (1994). Toward a unified conception of business ethics: Integrative social contracts theory. Academy of Management Review, 19, 252-284.

Eisenbeiß, S. A. (2012). Re-thinking ethical leadership: An interdisciplinary integrative approach. The Leadership Quarterly, 23, 791-808.

Eisenbeiß, S. A., \& Giessner, S. R. (2012). The emergence and maintenance of ethical leadership in organizations: A question of embeddedness? Journal of Personnel Psychology, 11, 7-19.

Enderle, G. (1987). Some perspectives of managerial ethical leadership. Journal of Business Ethics, 6, 657-663.

Fang, S. R., Huang, C. Y., \& Huang, S. W. L. (2010). Corporate social responsibility strategies, dynamic capability and organizational performance: Cases of top Taiwan-selected benchmark enterprises. African Journal of Business Management, 4, 120-132.

Fehr, R., Yam, K. C. S., \& Dang, C. (2015). Moralized leadership: The construction and consequences of ethical leader perceptions. Academy of Management Review, 40, 182-209.

Felner, E. (2012). Human rights leaders in conflict situations: A case study of the politics of 'moral entrepreneurs'. Journal of Human Rights Practice, 4, 57-81.

Finnemore, M., \& Sikkink, K. (1998). International norm dynamics and political change. International Organization, 52, 887-917.

Fishman, J. P. (2014). Copyright infringement and the separated powers of moral entrepreneurship. American Criminal Law Review, 51, 359-401.

French, J. P., \& Raven, B. (1959). The basis of social power. In D. Cartwright (Ed.), Studies in social power (pp. 150-167). Ann Arbor: University of Michigan.

Fuller, S. (2013). 'Never let a good crisis go to waste': Moral entrepreneurship, or the fine art of recycling evil into good. Business Ethics: A European Review, 22, 118-129.

Gillespie, N., \& Dietz, G. (2009). Trust repair after an organizationlevel failure. Academy of Management Review, 34, 127-145.

GSK. (2013). GSK announces changes to its global sales and marketing practices to further ensure patient interests come first. https://us.gsk.com/en-us/media/press-releases/2013/gsk- 
announces-changes-to-its-global-sales-and-marketing-practicesto-further-ensure-patient-interests-come-first/.

Gustafson, A. (2001). Advertising's impact on morality in society: Influencing habits and desires of consumers. Business and Society Review, 106, 201-223.

Halse, C., \& Honey, A. (2007). Rethinking ethics review as institutional discourse. Qualitative Inquiry, 13, 336-352.

Hargreaves, S. (2004). Conceptualizing legitimacy for new venture research. Journal of New Business Ideas and Trends, 2(2), $54-65$.

Hollows, J., \& Jones, S. (2010). 'At least he's doing something': Moral entrepreneurship and individual responsibility in Jamie's Ministry of Food. European Journal of Cultural Studies, 13, 307-322.

Hosmer, L. T. (1995). Trust: The connecting link between organizational theory and philosophical ethics. Academy of Management Review, 20, 379-403.

Hunt, A. (1997). 'Moral panic' and moral language in the media. British Journal of Sociology, 48, 629-648.

Jones, T. M. (1991). Ethical decision making by individuals in organizations: An issue-contingent model. Academy of Management Review, 16, 366-395.

Jordan, J., Brown, M. E., Treviño, L. K., \& Finkelstein, S. (2013). Someone to look up to: Executive-follower ethical reasoning and perceptions of ethical leadership. Journal of Management, 39, 660-683.

Kalshoven, K., Den Hartog, D. N., \& De Hoogh, A. H. B. (2011a). Ethical leadership at work questionnaire (ELW): Development and validation of a multidimensional measure. The Leadership Quarterly, 22, 51-69.

Kalshoven, K., Den Hartog, D. N., \& De Hoogh, A. H. B. (2011b). Ethical leader behavior and big five factors of personality. Journal of Business Ethics, 100, 349-366.

Kanungo, R. N., \& Mendonca, M. (1996). Ethical dimensions of leadership. Thousand Oaks: Sage Publications.

Kaptein, M. (2017). The battle for business ethics: A struggle theory. Journal of Business Ethics (to be published).

Keck, M. E., \& Sikkink, K. (2014). Activists beyond borders: Advocacy networks in international politics. Cornell: Cornell University Press.

Khuntia, R., \& Suar, D. (2004). A scale to assess ethical leadership for Indian private and public sector managers. Journal of Business Ethics, 49, 13-26.

Kim, P. H., Ferrin, D. L., Cooper, C. D., \& Dirks, K. T. (2004). Removing the shadow of suspicion: The effects of apology versus denial for repairing competence-versus integrity-based trust violations. Journal of Applied Psychology, 89, 104-118.

Kohlberg, L. (1969). State and sequence: The cognitive-development approach to socialization. In D. Goslin (Ed.), Handbook of socialization theory and research (pp. 347-480). Chicago: RandMcNally.

Kotter, J. (2007). What leaders really do. In R. Vecchio (Ed.), Leadership: Understanding the dynamics of power and influence in organizations (pp. 23-32). Notre Dame: University of Notre Dame Press.

Lawton, A., \& Páez, I. (2015). Developing a framework for ethical leadership. Journal of Business Ethics, 130, 639-649.

Mayer, D. M., Aquino, K., Greenbaum, R. L., \& Kuenzi, M. (2012). Who displays ethical leadership and why does it matter? An examination of antecedents and consequences of ethical leadership. Academy of Management Journal, 55, 151-171.

Mayer, D. M., Kuenzi, M., Greenbaum, R., Bardes, M., \& Salvador, R. (2009). How low does ethical leadership flow? Test of a trickle-down model. Organizational Behavior and Human Decision Processes, 108, 1-13.
Mo, S., \& Shi, J. (2017). Linking ethical leadership to employees' organizational citizenship behavior: Testing the multilevel mediation role of organizational concern. Journal of Business Ethics, 141(1), 151-162.

Nadelmann, E. A. (1990). Global prohibition regimes: The evolution of norms in international society. International Organization, 44, 479-526.

Nicholls, A., \& Cho, A. H. (2008). Social entrepreneurship: The structuration of a field. In A. Nicholls (Ed.), Social entrepreneurship: New models of sustainable social change (pp. 99-118). Oxford: Oxford University Press.

Nonet, P., \& Selznick, P. (1978). Law and society in transition: Toward responsive law. New Brunswick: Transaction Publishers.

Paine, L. (2003). Value shift: Why companies must merge social and financial imperatives to achieve superior performance. New York: McGraw Hill.

Palmer, D. E. (2009). Business leadership: Three levels of ethical analysis. Journal of Business Ethics, 88, 525-536.

Piccolo, R. F., Greenbaum, R., Den Hartog, D. N., \& Folger, R. (2010). The relationship between ethical leadership and core job characteristics. Journal of Organizational Behavior, 31, 259-278.

Pierce, J. L., \& Delbecq, A. L. (1977). Organization structure, individual attitudes and innovation. Academy of Management Review, 2, 27-37.

Reich, S. (2003). Power, institutions and moral entrepreneurs. No. 18739. University of Bonn: Center for Development Research.

Resick, C. J., Hanges, P. J., Dickson, M. W., \& Mitchelson, J. K. (2006). A cross-cultural examination of the endorsement of ethical leadership. Journal of Business Ethics, 63, 345-359.

Resick, C. J., Martin, G. S., Keating, M. A., Dickson, M. W., Kwan, H. K., \& Peng, C. (2011). What ethical leadership means to me: Asian, American and European perspectives. Journal of Business Ethics, 101, 435-457.

Rest, J. R. (1986). Moral development: Advances in research and theory. New York: Praeger.

Rost, J. C. (1995). Leadership: A discussion about ethics. Business Ethics Quarterly, 5, 129-142.

Rousseau, D. M., Sitkin, S. B., Burt, R. S., \& Camerer, C. (1998). Not so different after all: A cross-discipline view of trust. Academy of Management Review, 23, 393-404.

Rubin, R. S., Dierdorff, E. C., \& Brown, M. E. (2010). Do ethical leaders get ahead? Exploring ethical leadership and promotability. Business Ethics Quarterly, 20, 215-236.

Schein, E. H. (2010). Organizational culture and leadership. San Francisco: Wiley.

Schumacher, E. G., \& Wasieleski, D. M. (2013). Institutionalizing ethical innovation in organizations: An integrated causal model of moral innovation decision processes. Journal of Business Ethics, 113, 15-37.

Smith, A. W. (1993). Leadership: Developing leaders and organizations. Updating School Board Policies, 24(2), 1-4.

Smith, H. R., \& Carroll, A. B. (1984). Organizational ethics: A stacked deck. Journal of Business Ethics, 3, 95-100.

Starratt, R. J. (1999). Moral dimensions of leadership. In B. T. Begley \& P. E. Leonard (Eds.), The values of educational administration (pp. 23-35). London: Falmer Press.

Sunstein, C. R. (1996). Social norms and social roles. Columbia Law Review, 96, 903-968.

Taffinder, P. (1997). The new leaders: Achieving corporate transformation through dynamic leadership. London: Kogan Page Publishers.

Toor, S., \& Ofori, G. (2009). Ethical leadership: Examining the relationships with full range leadership model, employee 
outcomes, and organizational culture. Journal of Business Ethics, 90, 533-547.

Treviño, L. K., Brown, M. E., \& Hartman, L. P. (2003). A qualitative investigation of perceived executive ethical leadership: Perceptions from inside and outside the executive suite. Human Relations, 56, 5-37.

Treviño, L. K., Hartman, L. P., \& Brown, M. (2000). Moral person and moral manager: How executives develop a reputation for ethical leadership. California Management Review, 42(4), $128-142$.

Treviño, L. K., \& Nelson, K. A. (2010). Managing business ethics. New Jersey: Wiley.

Uhl-Bien, M., \& Carsten, M. K. (2007). Being ethical when the boss is not. Organizational Dynamics, 36, 187-201.

Van Gils, S., Van Quaquebeke, N., Van Knippenberg, D., Van Dijke, M., \& De Cremer, D. (2015). Ethical leadership and follower organizational deviance: The moderating role of follower moral attentiveness. The Leadership Quarterly, 26, 190-203.

Voegtlin, C., Patzer, M., \& Scherer, A. G. (2012). Responsible leadership in global business: A new approach to leadership and its multi-level outcomes. Journal of Business Ethics, 105, 1-16.

Walumbwa, F. O., Mayer, D. M., Wang, P., Wang, H., Workman, K., \& Christensen, A. L. (2011). Linking ethical leadership to employee performance: The roles of leader-member exchange, self-efficacy, and organizational identification. Organizational Behavior and Human Decision Processes, 115, 204-213.

Walumbwa, F. O., \& Schaubroeck, J. (2009). Leader personality traits and employee voice behavior: Mediating roles of ethical leadership and work group psychological safety. Journal of Applied Psychology, 94, 1275-1286.
Wolf, S. (1982). Moral saints. The Journal of Philosophy, 79, 419-439.

Wrage, S., \& Wrage, A. (2005). Multinational enterprises as "moral entrepreneurs" in a global prohibition regime against corruption. International Studies Perspectives, 6, 316-324.

Wu, L. Z., Kwan, H. K., Yim, F. H. K., Chiu, R. K., \& He, X. (2015). CEO ethical leadership and corporate social responsibility: A moderated mediation model. Journal of Business Ethics, 130, 819-831.

Wu, C., \& Wang, Y. (2011). Understanding proactive leadership. In W. H. Mobley, M. Li, \& Y. Wang (Eds.), Advances in global leadership (pp. 299-314). Emerald: Bingley.

Yukl, G., Mahsud, R., Hassan, S., \& Prussia, G. E. (2013). An improved measure of ethical leadership. Journal of Leadership \& Organizational Studies, 20, 38-48.

Yukl, G., Seifert, C. F., \& Chavez, C. (2008). Validation of the extended influence behavior questionnaire. The Leadership Quarterly, 19, 609-621.

Yurtsever, G. (2003). Measuring the moral entrepreneurial personality. Social Behavior and Personality: An International Journal, $31,1-12$.

Zheng, D., Witt, L. A., Waite, E., David, E. M., van Driel, M., McDonald, D. P., et al. (2015). Effects of ethical leadership on emotional exhaustion in high moral intensity situations. The Leadership Quarterly, 26, 732-748.

Zhu, W., He, H., Treviño, L. K., Chao, M. M., \& Wang, W. (2015). Ethical leadership and follower voice and performance: The role of follower identifications and entity morality beliefs. The Leadership Quarterly, 26, 702-718. 